\title{
Indicative drug budgets for general practitioners: a prescription for change
}

\author{
Bernie O’Brien
}

This article and the one that follows it by James Raftery are the eleventh and twelfth in a series of articles on the white paper Working for Patients and its accompanying working papers. The series started on 18 February (p 437)
The white paper Working for Patients was published in January ${ }^{1}$; the eight working papers followed nearly a month later. Working paper No 4 explains the reasoning behind the proposals to give general practitioners indicative prescribing budgets. ${ }^{2}$ The perceived problem and the objective of the new policy are stated concisely:

It is generally recognised that some prescribing is wasteful or unnecessarily expensive. The objective of the new arrangements is to place downward pressure on expenditure on drugs in order to eliminate this waste and to release resources for other parts of the health service.

\section{The problem}

Expenditure on the family practitioner services was just over $£ 5$ billion in 1987-8 and the services account for $24 \%$ of total NHS spending. At $£ 1.9$ billion, the drugs bill is the single largest item of family practitioner services expenditure: in any given year more is spent on medicines than on the doctors who prescribe them.

\section{... the government is treating the symptoms of health care cost inflation rather than the cause.}

Although the proportion of NHS expenditure on pharmaceuticals has remained fairly constant over the past 25 years, the aging population and the introduction of new and more expensive medicines is creating upward pressure on the drugs bill.

The problem is not simply a concern with the absolute level of spending; the question is an evaluative one of value for money or cost effectiveness. The belief underlying the present proposals is that the prescribing of medicines could be more cost effective-that is, the same level of patient benefits could be generated but at a lower level of expenditure. Similar economic reasoning can be found in the earlier primary care white paper where it was claimed that the introduction of the selected list in 1985, restricting the availability of several products on NHS prescription, resulted in an annual saving of $£ 75$ million, and that this saving was achieved without detriment to patient care.

But when a government seeks to restrict arbitrarily for cost reasons which products may be prescribed by general practitioners it is treating the symptoms of health care cost inflation rather than the cause. At the heart of the problem is the fact that general practitioners have had little inc̈ntive in the past to consider the costs of their prescribing either in terms of its frequency or content. Unlike the cash limited hospital sector, where there is a strong incentive for pharmacies to dispense cheaper generic equivalents rather than brand name drugs, the financial consequences of higher prescribing costs are not borne by individual family practitioner committees or general practitioner practices. Such general practitioner prescribing freedom has contributed to wide differences in prescribing practices and costs which cannot be wholly explained in terms of patient demography and morbidity. In 1986-7, for example, drug expenditures varied from $£ 26$ per head of population in one family practitioner committee to $£ 40$ in another, ${ }^{1}$ and variability between general practitioner practices is likely to be even greater.

The proposed solution to the problem is that by giving general practitioners prescribing budgets, in addition to the detailed information on their prescribing habits already planned under the primary care white paper, the incentives for cost conscious prescribing are created.

\section{The proposals}

- Regional health authorities will be allocated annual budgets to cover expenditure on medicines and appliances in the family practitioner services within the region. Remuneration for pharmacies and dispensing doctors will not be included in drug budgets nor will budgets take account of income from prescription charges. Regional health authorities will pass on drug budgets to family practitioner committees, which will be responsible for setting indicative drug budgets for individual practices. (Those with lists of more than 11000 who have elected to receive practice budgets will have an allowance within this for drugs.)

- After a period of transition allocations to regional health authorities and family practitioner committees will be on the basis of resident population using a weighted capitation formula. Factors in the allocation formula will include the age and sex of patients, morbidity; temporary residents, and cross boundary flows. The relative weights to be attached to these factors and the addition of other factors deemed relevant are yet to be determined.

- The weighted capitation formula will also form the basis for family practitioner committees setting indicative budgets for general practitioner practices. Again the formula may be extended to allow for local social and epidemiological factors that may influence the demand for drugs. Furthermore, the working paper notes that factors such as referral rates of patients to hospital, special interests of practices, and patients in need of unusually expensive medicines will need to be taken into account.

- The level at which the family practitioner committee sets an indicative drug budget for an individual practice will depend on the factors outlined above and a comparison of the practice's current prescribing with the average level for broadly comparable practices in the same family practitioner committee. "Generally, where the current level is higher than the average, the indicative budget will be set somewhere between the two figures" (para 2.5). Therefore the overall aim of the procedures is to bring downward pressure on practices with above average prescribing costs where the differences in prescribing "cannot be explained by the composition of their practice lists or other accepted factors." 
- Joint formularies between family practitioner committees and hospitals in an NHS district are to be encouraged so that "both hospital doctors and general practitioners are guided to use the same medicines."

- General practitioner practices will be required to monitor their prescribing and cost information and provide monthly returns to the family practitioner committee; in turn the family practitioner committees must develop information systems for monitoring and comparing the activity and cost data across general practitioner practices.

- An incentive scheme will operate. General practitioner practices in a family practitioner committee can aim for expenditure lower than the drug budget allocated to the family practitioner committee by the region, and where such targets are achieved the family practitioner committee will keep half the savings to be spent on primary care improvement schemes within the committee's area.

- Where general practitioner practices overspend on indicative drug budgets a process of discussion with the family practitioner committee and peer review will be entered into, and if this fails the ultimate sanction is to withhold remuneration from the doctors concerned.

\section{Bold prescription for change}

The proposals offer a bold prescription for change. Taken in conjunction with the proposed policy of realigning family practitioner committees to be accountable to regional health authorities, drug budgeting and the other general practitioner reforms offer an important step towards the integration of primary care with the rest of the NHS in terms of resource allocation, management, and accountability.

The indicative drug budget proposals are designed to build on the Prescribing Analysis and Cost information system proposed in the earlier primary care white paper. The working paper claims that this quarterly feedback to general practitioners on their prescribing and costs from the Prescription Pricing Authority "has increased awareness among general practitioners of the cost of their prescribing decisions." Indeed, there is some evidence which suggests that, even without the use of budgets, such passive information feedback can modify prescribing behaviour in some doctors. ${ }^{4} \mathrm{~A}$ good example of differential cost awareness can be found with dispensing general practitioners compared with their non-dispensing colleagues: data for 1986 indicates that although these groups have the same prescribing rate per caput (7.1), the net ingredient cost per prescription is lower for doctors who dispense their own medicines and are aware of such costs. ${ }^{56}$ But although awareness may generate self audit and modified prescribing among the motivated minority, the burden of evidence from hospital studies of feeding back cost information to doctors is that raised awareness is a necessary but not sufficient condition for behaviour change. ${ }^{7}$ Correspondingly, the current proposals endorse the view that such feedback needs to be reinforced with budgetary incentives and sanctions.

Although the idea of drug budgets for general practitioners has been around for some time ${ }^{8}$ the present proposals state that budgets will be indicative rather than binding. This careful qualification sounds an understandable note of caution in expectation of the difficulties of setting drug budgets using weighted capitation formulae. Population characteristics may explain only part of the variation in prescribing; several studies have shown that a range of characteristics of doctors are correlated with prescribing behaviour in addition to external influences such as promotion by the pharmaceutical industry. ${ }^{910}$ Given such statistical uncertainties a good deal of flexibility will be built into the process of budget setting. As is currently the case in the policing of prescribing by regional medical officers, a key focus will be how far above average a practice's prescribing is when compared with similar practices in the area, and whether the excess can be explained in terms of the composition of practice lists or other factors.

The weighted capitation formula is a key element in the proposed allocation criteria and is similar in conception to the Resource Allocation Working Party's formula for revenue allocations to NHS regions (although this too will be simplified under the white paper proposals). ${ }^{11}$ The rationale is that variation in the need for prescription drugs can be adequately modelled

\section{. . lower list sizes will simply result in more, rather than longer, consultations.}

as a function of population characteristics for the purpose of budget allocations. But factors such as age and sex are more easily measured than others such as morbidity, although this latter may explain a significant proportion of prescribing variance. No guidance is given as to what measures of morbidity would be used. Standardised mortality rates are unlikely to be good predictors of primary care prescribing, but alternatives such as general practitioner consultation rates are measures of utilisation and workload rather than morbidity. An important feature of the morbidity measure(s) chosen to reflect prescribing costs is that it is sensitive to the prevalence as well as to the incidence of disease. In 1986, for example, the net ingredient cost of drugs for chronic conditions such as rheumatism is $£ 8.88$ per item compared with $£ 3.18$ for drugs to treat infections.

\section{Need for longer consultations?}

The predicted impact of drug budgets is that they will create an incentive for the general practitioner to reduce the frequency of prescribing and to substitute less costly (typically generic) items for the more expensive brand name products. Generic substitution of equivalent efficacy drugs creates no obvious additional burden for the general practitioner, except in remembering some of the more complex generic names. (The long term impact of generic substitution on drug industry research and development is a subject for another debate). But attempting to reduce the rate of prescribing, without an adverse impact on the quality of care, may require the substitution of some other factor in its place, such as the general practitioners' time in a longer period of consultation. ${ }^{12}$ Although the decline in average list sizes - from 2291 patients per doctor in 1976 to 1988 in 1986-might enable consultations to extend beyond the average six minutes, ${ }^{13}$ recent survey evidence suggests that lower list sizes will simply result in more, rather than longer, consultations. ${ }^{14}$ Furthermore, there is an obvious concern that unless the budget criteria fully compensate for high drug cost patients (in type or number of scripts), such patients may not be viewed by general practitioners as attractive additions to their list.

The family practitioner committee is the focal point for the exercise of financial incentives and sanctions. It is the family practitioner committee which keeps half the difference of any underspend against the drug budget set by the region. What is not clear from the 
working paper is whether the reward is for aggregated underspending by a family practitioner committee or whether all general practitioner practices should have an expenditure outturn within, say, $5 \%$ of budget. The sanction of last resort against those practices which overspend on their drug budget is to withhold doctors' remuneration. Such action is likely to create some interesting contractual problems because it is the individual doctor who is in contract with the family practitioner committee but the practice which will hold the indicative drug budget.

In conclusion, little indication is given in the working paper as to how the success or failure of the proposals will be evaluated. If the test is to be one of improved cost effectiveness the monitoring of reduced drug expenditure alone is inadequate. Data are required on the quality of patient care and treatment outcomes to determine whether they can be maintained, or even improved, at lower cost. The proposals are to be tried out in 1990-1; I hope that comparative trials will be designed to address questions of effectiveness as well as of cost.
1 Secretaries of State for Heath, Wales, Northern Ireland, and Scotland. Working for patients. London: HMSO, 1989. (Cmnd 555.)

2 Secretaries of State for Health, Wales, Northern Ireland, and Scotland. Indicative prescribing budgets for general medical practitioners. Working papers N.4. London: HMSO, 1989.

3 Secretaries of State for Social Services, Wales, Northern Ireland, and Scotland. Promoting better health. London: HMSO, 1987. (Cmnd 249.)

4 Harris CM, Jarman B, Woodman E, White P, Fry JS. Prescribing - a suitable case for treatment. London: Royal College of General Practitioners, 1984.

5 Department of Health and Social Security. Statistics for general medical practitioners in England and Wales: 1976 to 1986. London: Government practitioners in England
statistical service, 1988.

6 Office of Health Economics. Compendium of health statistics. 6th ed. London Office of Health Economics, 1987.

7 Wickings I, Coles JM, Flux R, Howard L. Review of clinical budgeting and costing experiments. Br Med f 1983;286:575-7.

8 Wade OL. Prescribing. In: Phillips CI, Wolfe JN, eds. Clinical practice and economics. London: Pitman Medical, 1976.

9 Hemminki E. Review of the literature on the factors affecting drug prescribing. Social Science and Medicine 1975;9:111-5.

10 Worthen DB. Prescribing influences: an overview. British fournal of Medical Education 1973;7:109-17.

11 Department of Health and Social Security. Sharing resources for health in England. Report of the resource allocation working party. London: HMSO, 1976.

12 Murray TS, Barber JH, Hannay DR. Consulting time and prescribing rates. Update 1978;16:969-75.

13 Wilson AD. Consultation length: general practitioner's attitudes and practices. BrMed f 1985;290:1322-4.

14 Butler JR, Calnan MW. List sizes and use of time in general practice. Br Med $\mathcal{F}$ 1987;295:1383-6.

\title{
Distinction and merit awards: a $£ 100 \mathrm{~m}$ management tool?
}

\author{
James Raftery
}

The system of distinction and merit awards, which grew out of an agreement in 1948 between Anuerin Bevan and Lord Moran, president of the Royal College of Physicians, has survived with few changes for the $\mathbf{4 0}$ years up to the recent NHS review.'

The white paper proposes that discussions should begin with the medical profession with the following changes in mind:

- To modify the criteria for $\mathrm{C}$ awards so that in future consultants must show not only their clinical skills but also a commitment to the development and management of the service

- To restrict progression of the remaining three levels of awards to those who have earned $\mathrm{C}$ awards

- To change the composition of the regional committees which nominate candidates for $\mathrm{C}$ awards. In future, each committee will be chaired by the regional health authority chairman and will include senior managers as well as clinicians

- To change the composition of the national Advisory Committee on Distinction Awards to provide for stronger management influence on the choice of award holders

- To make the new or increased awards reviewable every five years

- To make new or increased awards pensionable only if a consultant continues working in the NHS for at least three years.

The brief, 11 page, working paper provides details on some of the organisational changes envisagednamely, that nominations for $\mathrm{C}$ awards would be expected to have the support of both clinicians and management and that membership of the Advisory Committee on Distinction Awards be supplemented by a senior person with experience of NHS management. ${ }^{2}$ Thus, management will have a veto on the nominations for $\mathrm{C}$ awards as well as a greater input to the allocation of higher awards.

Epidemiology and Socia Medicine, St George's Hospital Medical School, London SW17 ORE

James Raftery, MA, lecturer

in health economics

BrMed F 1989;298:946-8 publication of the first detailed description of its working ${ }^{3}$ and questions in parliament about the cost of the system. The House of Commons social services select committee, which suggested in 1983 that major change in the distinction awards might be salutary, has announced its plans to review the award system.

\section{... the continuation of merit awards on top of locally determined salaries in the NHS trusts seems anomalous.}

From its beginnings the award system has been controversial. It was seen in 1950 by the Treasury as a "blot on the landscape of public finance," which was accepted only on the grounds that "arguments of expediency outweigh those of principle." ${ }^{4}$ Extraordinary secrecy surrounded the awards, with the first limited information about the distribution of awards by specialty only becoming available in 1958 in response to parliamentary questions. Secrecy and the uneven distribution of awards by specialty, region, and sex have been the main subjects of subsequent criticism.

In a series of articles two of the more persistent critics concluded that the system should be abolished because "it remains immutably unfair, divisive and, in its secrecy, contemptible. No other profession would copy this system and consultants would gain respect by scrapping it-especially self respect." ${ }^{\text {-7 }}$ Other critics have echoed these points in more temperate language.

The first official criticism of the awards scheme emerged in 1988 when the review body on doctors' and dentists' remuneration, having expressed concern that the awards should benefit the NHS as well as reward individuals, suggested that awards should have an age limit and be subject to review with a greater managerial input into the selection process. The working paper on merit awards makes it clear that the white paper's proposals are based largely on these suggestions. 